\title{
Everolimus Exposure and Early Metabolic Response as Predictors of Treatment Outcomes in Breast Cancer Patients Treated with Everolimus and Exemestane
}

\author{
Annelieke E. C. A. B. Willemsen ${ }^{1}$ (D) - Lioe-Fee de Geus-Oei ${ }^{2,3} \cdot$ Maaike de Boer $^{4} \cdot$ Jolien Tol $^{5} \cdot$ Yvonne Kamm $^{6}$ • \\ Paul C. de Jong ${ }^{7}$ - Marianne A. Jonker ${ }^{8}$ - Allert H. Vos $^{9} \cdot$ Willem Grootjans ${ }^{2}$ - Johannes W. B. de Groot ${ }^{10}$. \\ Sasja F. Mulder ${ }^{1}$. Erik H. J. G. Aarntzen ${ }^{11}$ • Winald R. Gerritsen ${ }^{1}$. Carla M. L. van Herpen ${ }^{1}$ - Nielka P. van Erp ${ }^{12}$
}

Published online: 27 September 2018

(C) The Author(s) 2018

\begin{abstract}
Background Treating breast cancer patients with everolimus and exemestane can be challenging due to toxicity and suboptimal treatment responses.

Objective We investigated whether everolimus exposure and early metabolic response are predictors for toxicity and effectiveness in these patients.

Patients and Methods We performed pharmacokinetic assessments 14 and 35 days after starting treatment. $\left[{ }^{18} \mathrm{~F}\right]$ fluorodeoxyglucose-positron emission tomography $\left({ }^{18} \mathrm{~F}\right.$-FDG-PET) was performed at baseline, and 14 and 35 days after the start of the therapy. We recorded toxicity, defined as dose interventions within 3 months, and progression-free survival (PFS). Results Among 44 evaluable patients, the geometric mean (GM) $\mathrm{C}_{\text {trough }}$ was higher in patients with toxicity compared to patients without (17.4 versus $12.3 \mu \mathrm{g} / \mathrm{L}(p=0.02))$. The optimal cut-off value to predict toxicity was $\mathrm{C}_{\text {trough }}>19.2 \mu \mathrm{g} / \mathrm{L}$. $\mathrm{GM} \mathrm{C}_{\text {trough }}$ of patients with and without progressive disease (PD) within 3 months was not significantly different $(12.0$ versus $15.2 \mu \mathrm{g} / \mathrm{L}(p=$ $0.118)$ ). In 28 evaluable patients, PD within 3 months could best be predicted using the percentage decrease in peak standardized uptake value normalized by lean body mass of the lesion with highest FDG uptake ( $\mathrm{SUL}_{\text {peak high }}$ ) at day 14. Patients with $<11 \%$ versus $>11 \%$ decrease in $\mathrm{SUL}_{\text {peak high }}$ at day 14 had a median PFS of 90 days versus 411 days, respectively $(p=0.0013)$ and more frequently had PD within 3 months: 70 vs $11 \%$, respectively.

Conclusions Our results show that everolimus toxicity is related to everolimus $\mathrm{C}_{\text {trough }}$. No relation was observed between everolimus exposure and treatment effectiveness. An early FDG-PET can identify patients at high risk of nonresponse. These results warrant further validation. Clinicaltrials.gov identifier: NCT01948960.
\end{abstract}

Electronic supplementary material The online version of this article (https://doi.org/10.1007/s11523-018-0596-8) contains supplementary material, which is available to authorized users.

Nielka P. van Erp

Nielka.vanerp@ radboudumc.nl

1 Department of Medical Oncology, Radboud Institute for Health Sciences, Radboud university medical center, Nijmegen, the Netherlands

2 Department of Radiology, Leiden University Medical Center (LUMC), Leiden, the Netherlands

3 Biomedical Photonic Imaging Group, MIRA Institute, University of Twente, Enschede, the Netherlands

4 Division of Medical Oncology, Department of Internal Medicine, GROW-School of Oncology and Developmental Biology, Maastricht University Medical Center, Maastricht, the Netherlands

5 Department of Medical Oncology, Jeroen Bosch Hospital, 's-Hertogenbosch, the Netherlands
6 Department of Medical Oncology, Maasziekenhuis Pantein, Boxmeer, the Netherlands

7 Department of Medical Oncology, St. Antonius Ziekenhuis, Utrecht, the Netherlands

8 Department for Health Evidence, Radboud university medical center, Nijmegen, the Netherlands

9 Department of Medical Oncology, Bernhoven Ziekenhuis, Uden, the Netherlands

10 Isala Oncology Center, Zwolle, the Netherlands

11 Department of Radiology and Nuclear Medicine, Radboud university medical center, Nijmegen, the Netherlands

12 Department of Pharmacy, Radboud Institute for Health Sciences, Radboud university medical center, P.O. Box 9101, 6500 HB Nijmegen, the Netherlands 


\section{Key Points}

In breast cancer patients treated with everolimus and exemestane, everolimus $\mathrm{C}_{\text {trough }}$ is an important predictor of toxicity, as patients with $\mathrm{C}_{\text {trough }}>19.2 \mu \mathrm{g} / \mathrm{L}$ have a higher risk of clinically relevant toxicity.

A lack of decrease in metabolic activity measured by FDG-PET/CT after 14 days of treatment can identify a subgroup of patients at high risk of nonresponse, for whom an early adjustment of therapy or extra follow-up could be considered.

\section{Introduction}

The introduction of the combination treatment of everolimus and exemestane markedly improved clinical outcomes in patients with hormone receptor positive metastatic breast cancer (mBC) [1]. Since the BOLERO-2 study, several trials have subsequently confirmed the beneficial effect on treatment outcomes in these patients [2-4]. Unfortunately, not all patients benefit from this treatment. In the BOLERO-2 study, $10 \%$ of patients had progressive disease (PD) as best overall response and the clinical benefit rate (stable disease, partial response, and complete response) for $\geq 24$ weeks was only $51 \%$ [5].

Importantly, patients treated with this regimen can experience severe everolimus-induced side effects, as $27 \%$ of patients experience grade 3 or 4 toxicity [6]. Moreover, low grade toxicities have a significant impact on the quality of life of these patients as well and can necessitate dose adjustments. Therefore, treating breast cancer patients with everolimus can be challenging. Early prediction of toxicity and nonresponse would greatly facilitate clinical decision-making. Everolimus exposure, patient characteristics, and early metabolic response could be predictors for toxicity and response and may be used as pharmacokinetic and pharmacodynamic biomarkers. Currently, these biomarkers are not used in routine clinical practice.

Everolimus for $\mathrm{mBC}$ patients is prescribed at a fixed dose, but shows substantial interindividual variation in drug exposure of 36-45\% [7-10]. Evidence is mounting that the everolimus trough concentration $\left(\mathrm{C}_{\text {trough }}\right)$ is an important predictive factor for toxicity and effectiveness [11-14]. The largest study so far, with 938 patients with solid tumors, showed that a twofold increase in everolimus $\mathrm{C}_{\text {trough }}$ increased the likelihood of tumor size reduction by approximately $40 \%$ [12]. In patients with $\mathrm{mBC}$, metastatic renal cell carcinoma (mRCC), or neuro-endocrine tumors, an everolimus $\mathrm{C}_{\text {trough }}>$ $11.9 \mu \mathrm{g} / \mathrm{L}$ was associated with a threefold increase in progression free survival (PFS) and a $\mathrm{C}_{\text {trough }}<26.3 \mu \mathrm{g} / \mathrm{L}$ was associated with a fourfold decreased risk of toxicity [11].
Patient characteristics can be relevant, as subgroups such as obese or elderly patients can show different pharmacokinetics compared to other patients. Obesity can lead to an increased volume of distribution, increased hepatic blood flow, higher CYP3A4 activity, and a change in plasma binding $[15,16]$. Everolimus pharmacokinetics in elderly patients can differ as a result of decreased absorption due to gastric atrophy, lower first pass effect due to a decrease in hepatic blood flow, and reduced CYP3A4 activity [17-20]. The net result of all these influences on drug disposition in obese or elderly patients is yet unknown.

Functional imaging to assess metabolic response could serve as an early biomarker for the evaluation of response to treatment. The inhibition of activity of oncogenic proteins by everolimus and exemestane can result in rapid metabolic changes. These metabolic changes can be detected using $\left[{ }^{18} \mathrm{~F}\right]$ fluorodeoxyglucose-positron emission tomography (FDG-PET). Early detection of nonresponse to treatment can facilitate early decision making, including dose adjustments or a change of therapy. Preclinical data suggest that FDG-PET is a suitable imaging modality for response assessment to everolimus treatment [21-25]. A clinical study of FDG-PET changes in $\mathrm{mRCC}$ patients treated with everolimus showed a modest correlation between metabolic changes and change in tumor size [26]. In mBC patients on endocrine therapy or chemotherapy, metabolic response on FDG-PET was a good predictor of PFS $[27,28]$. For $\mathrm{mBC}$ patients treated with everolimus and exemestane, to the best of our knowledge, no clinical study assessing the predictive value of FDG-PET for treatment response has yet been published.

The current study aimed to investigate whether everolimus exposure is related to the development of toxicity and treatment effectiveness in patients with $\mathrm{mBC}$. We hypothesized that a therapeutic window for everolimus can be established, in which the balance between toxicity and effectiveness is optimal. Additionally, we explored whether early FDG-PET evaluation can be used as an early read-out for effectiveness. In this way, an ineffective therapy could be stopped earlier, preventing unnecessary toxicity and costs.

\section{Materials and Methods}

\subsection{Patients and Study Design}

The present study was an explorative, prospective, open-label, comparative study carried out in six hospitals in the Netherlands. We included women planning to start treatment with exemestane and everolimus. Patients using medication recognized as being strong inhibitors or inducers of CYP3A isoenzymes were excluded and no such medication was allowed during the study. 
Patients could participate either in the pharmacokinetic part of the study or in the combined pharmacokinetic and imaging part. For the pharmacokinetic part, patients were enrolled in three subgroups: control $(<70$ years and body mass index (BMI) $\left.<30 \mathrm{~kg} / \mathrm{m}^{2}\right)$, obese $\left(<70\right.$ years and BMI $\left.\geq 30 \mathrm{~kg} / \mathrm{m}^{2}\right)$, and elderly ( $\geq 70$ years and BMI $<30 \mathrm{~kg} / \mathrm{m}^{2}$ ). Planned enrollment was 25 patients per subgroup, but due to slow recruitment the study closed earlier. For the combined pharmacokinetic and imaging part, 40 patients were planned for inclusion. In the imaging part of the study, patients who were elderly and obese could also be included. The study protocol was approved by the Radboudumc Ethics Committee (reference number 2013-284) and registered as clinicaltrials.gov identifier: NCT01948960. All patients gave written informed consent. The study was performed in accordance with the Declaration of Helsinki.

\subsection{Clinical Evaluation}

We recorded baseline characteristics, including previous treatments. Clinical evaluation took place before the start of therapy, and after 14, 35, 60, and 90 days of treatment. Response assessment was performed with $\mathrm{CT}$ of chest and abdomen at baseline, and subsequently every three months. On the physician's discretion, additional investigations, such as bone scintigraphy, could be performed. Follow-up took place until progressive disease (PD) (even if everolimus or exemestane were discontinued earlier) and the reason for treatment discontinuation was recorded. PFS was defined as the time from start of treatment until PD or death. PD was assessed using Response Evaluation Criteria in Solid Tumors (RECIST) 1.1 [29]. If RECIST assessment was not possible, PD was assessed by other imaging techniques, CA 15.3 marker, or was clinically determined. If patients had PD within 14 days after stopping everolimus treatment, patients were scored as PD on treatment. Patients were censored for PFS and time to dose change event at time of everolimus discontinuation.

We recorded adverse events using Common Terminology Criteria for Adverse Events 4.0. We considered adverse events leading to a dose change clinically most relevant. Therefore, we defined toxicity as adverse events requiring a dose change within 3 months after start of treatment. All dose changes were recorded until discontinuation of treatment. In our analysis, we included all dose reductions or dose discontinuations that were a result of toxicity at least probably related to everolimus. Temporary drug interruptions without dose changes were not included.

\subsection{Pharmacokinetic Analysis and Intervention}

We performed everolimus pharmacokinetic assessment after 14 days of treatment. In the imaging part, a second pharmacokinetic assessment was performed at day 35 . In the case of dose interruptions, treatment had to be restarted at least 7 days prior to pharmacokinetic assessment to ensure steady state pharmacokinetics. Blood samples were collected before $\left(\mathrm{C}_{\text {trough }}\right)$ and $1,2,3,5$, and $8 \mathrm{~h}$ after administration of everolimus. The trough sample was extrapolated as a $24 \mathrm{~h}$ sample. The area under the concentration time curve $\left(\mathrm{AUC}_{0-24 \mathrm{~h}}\right)$ was calculated using a noncompartmental trapezoidal approach (Phoenix WinNonlin v6.3®). We measured everolimus concentrations in whole blood by a validated liquid chromatography tandem mass spectrometry technique.

Patients in the imaging part who had a low everolimus $\mathrm{AUC}_{0-24 \mathrm{~h}}(<550 \mu \mathrm{g} * \mathrm{~h} / \mathrm{L})$ at day 14 were randomized 2:1 to have a dose escalation or not $[7,8]$. Dose escalation was calculated to achieve an AUC $>550 \mu \mathrm{g} * \mathrm{~h} / \mathrm{L}$. Patients in whom the dose was escalated were excluded for the analysis of the relationship between $\mathrm{C}_{\text {trough }}$ and toxicity and effectiveness.

\subsection{FDG-PET Acquisition and Analysis}

In the imaging part of the study, patients underwent FDG-PET at baseline, and after 14 and 35 days of treatment. Activity was analyzed using standardized uptake values normalized by lean body weight (SUL), using the Janmahasatian formula [30]. We performed analysis by PERCIST criteria [31]. We measured $\mathrm{SUL}_{\text {peak }}$ (mean SUL in a volume of interest (VOI) of $1 \mathrm{~cm}^{3}$ ) and $\mathrm{SUL}_{\max }$ (voxel with highest activity). For five target lesions we determined the sum of the $\mathrm{SUL}_{\max }$ (sumSUL $L_{\text {max }}$ ) and the sum of the $\mathrm{SUL}_{\text {peak }}\left(\right.$ sumSUL $_{\text {peak }}$ ), and the $\mathrm{SUL}_{\text {peak }}$ of the lesion with the highest uptake

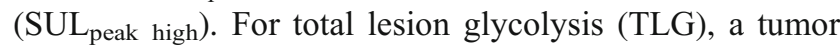
VOI was determined with a threshold of minimally two times mean activity of selected reference tissue. TLG then was defined as the mean uptake times the volume of this VOI, and the sum for up to five lesions was determined (sumTLG). Additionally, a qualitative judgment was performed independently by two nuclear medicine physicians.

Further details can be found in the Supplementary Material.

\subsection{Statistical Analyses}

Before statistical tests were performed, $\mathrm{C}_{\text {trough }}$ data were $\log$ (base 10) transformed, in order to obtain more symmetrically distributed data. A two sample t-test based on the transformed data was used to test for differences in the mean $\mathrm{C}_{\text {trough }}$ between patients with and without toxicity and response. To test for differences in the mean of the transformed $\mathrm{C}_{\text {trough }}$ between the three subgroups (control, obese, elderly), a one-way ANOVA was used, followed by post-hoc analysis (equality of variances was tested with Bartlett's test). No Bonferroni adjustment was performed for this post-hoc analysis, as this is an explorative study.

For the analyses described below, the untransformed $\mathrm{C}_{\text {trough }}$ data were used. The association between $\mathrm{C}_{\text {trough }}$ and 
age and BMI were analyzed, first visually and next with a multivariable linear regression model with $\mathrm{C}_{\text {trough }}$ as dependent variable and age and BMI as independent variables. For the association of $\mathrm{C}_{\text {trough }}$ with toxicity and effectiveness, receiver operating characteristic (ROC) curve analysis was performed and the AUC was determined. Optimal cut-off values were determined using the Youden index, the value associated with the highest sum of sensitivity + specificity -1 . The correlation between $\mathrm{C}_{\text {trough }}$ and metabolic change on FDG-PET was estimated with Spearman's correlation.

PFS and the time to dose change were estimated by the Kaplan-Meier estimator. A log rank test was performed to test whether the survival curves were significantly different. Two separate multivariable Cox proportional hazards regression models were fitted for PFS and the time to dose change, using backward selection based on a likelihood ratio test with $p>.10$ for removal. Age and BMI were used as covariates for the analysis of time to a dose change event. The ROC analysis was used to assess which variable of everolimus exposure and which variable of metabolic change had the strongest association with PD within 3 months. These variables were then used as covariates in the multivariable model for the analysis of time to PFS. Model assumptions, including proportional hazards and linearity, were checked and if needed the model was adjusted. Furthermore, the number of previous treatments was added in this model as a covariate, as this generally is a significant predictor of PFS.

Analyses were performed with SPSS v22 and graphs were created using GraphPad Prism v5.03.

\section{Results}

\subsection{Study Subjects}

Between October 2013 and October 2017, we enrolled 61 subjects. Four patients dropped out due to screen failure and from two patients we could not obtain pharmacokinetic data. The remaining 55 patients were subdivided into 34 control patients, ten obese patients, nine elderly patients, and two patients that were elderly and obese. Baseline characteristics of these patients are presented in Table 1 . Twenty patients had an $\mathrm{AUC}_{0-24 \mathrm{~h}}<550 \mu \mathrm{g} * \mathrm{~h} / \mathrm{L}$, and 14 patients were randomized to have dose escalation. In three patients dose escalation was not executed, as everolimus treatment had already been interrupted or discontinued. Therefore, 44 patients were suitable for analysis of the relationship between everolimus $\mathrm{C}_{\text {trough }}$ and toxicity; 43 patients were evaluable for the relationship between everolimus $\mathrm{C}_{\text {trough }}$ and effectiveness, as one patient had used exemestane pretreatment, which was not allowed in the study. In four out of these 43 patients, PD was established based on imaging or clinical aspects, as RECIST assessment was not possible. In the imaging part of the study, 39 patients were included. Of these, 29 patients had lesions with sufficient FDG avidity at baseline and were eligible to proceed for metabolic response monitoring using FDG-PET. From one of these 29 patients no FDG-PET was performed at day 14.

\subsection{General Pharmacokinetics of Everolimus}

In the 55 patients, the geometric mean $(\mathrm{GM}) \mathrm{C}_{\text {trough }}$ was $12.6 \mu \mathrm{g} / \mathrm{L}$ (range $4.6-37.5 \mu \mathrm{g} / \mathrm{L}$ ) and $\mathrm{AUC}_{0-24 \mathrm{~h}}$ was $565 \mu \mathrm{g} * \mathrm{~h} / \mathrm{L}$ (range $261-1162 \mu \mathrm{g} * \mathrm{~h} / \mathrm{L}$ ). $\mathrm{C}_{\text {trough }}$ was a good predictor of $\mathrm{AUC}_{0-24 \mathrm{~h}}$, with coefficient of determination $\left(r^{2}\right)=0.84(p<0.001)$. Nineteen patients had everolimus concentrations measured at 2 and 5 weeks, without a concurrent dose change. In these patients, the intra-individual coefficient of variation for everolimus at day 14 and day 35 was low: $16.8 \%$ for $\mathrm{C}_{\text {trough }}$ and $14.8 \%$ for $\mathrm{AUC}_{0-24 \mathrm{~h}}$.

\subsection{Main Outcomes}

\subsubsection{Relationship of $C_{\text {trough }}$ and Toxicity}

The reason for everolimus discontinuation was PD in $70 \%$ of patients, versus $30 \%$ due to toxicity. A dose change due to toxicity within 3 months occurred in $45 \%$ of patients. The median time to the first dose change was 52 days (9-159 days). Of 24 patients with a dose change event, this occurred in the first 14 days of treatment in only two patients. No dose changes occurred after day 159 of treatment. The most frequent reason for a dose change or interruption was stomatitis and the most frequent reason for discontinuation was pulmonary toxicity. Patients with a dose change $<3$ months had a significantly higher $\mathrm{GM} \mathrm{C}_{\text {trough }}$ compared to patients without a dose change $<3$ months: $17.4 \mu \mathrm{g} / \mathrm{L}$ and $12.3 \mu \mathrm{g} / \mathrm{L}$, respectively $(p=0.02)$. ROC analysis to predict dose change using $\mathrm{C}_{\text {trough }}$ showed an AUC of $0.71(p=0.02) . \mathrm{C}_{\text {trough }}$ was a slightly better predictor of toxicity than $\mathrm{AUC}_{0-24 \mathrm{~h}}$, with an AUC of 0.66. Optimal cut-off value was $C_{\text {trough }}>19.2 \mu \mathrm{g} / \mathrm{L}$, with sensitivity $55 \%$ and specificity $92 \%$. Thirteen out of 44 patients $(30 \%)$ had a $\mathrm{C}_{\text {trough }}$ above this threshold. Eleven out of these 13 patients $(85 \%)$ had toxicity leading to a dose change $<3$ months, compared to nine out of 31 (29\%) patients who did not develop toxicity, resulting in a relative risk of 2.9. Median time to first dose adjustment was significantly shorter for patients with $C_{\text {trough }}>19.2 \mu \mathrm{g} / \mathrm{L}$ compared to patients with $\mathrm{C}_{\text {trough }}<19.2 \mu \mathrm{g} / \mathrm{L}, 42$ days versus not reached, $p=0.0008$ (Fig. 1), hazard ratio (HR) 5.8 (95\% CI 2.1-16.1). When a cut-off of $26.3 \mu \mathrm{g} / \mathrm{L}$ was used, as proposed previously [11], median time to first dose adjustment for patients with $\mathrm{C}_{\text {trough }}>26.3 \mu \mathrm{g} / \mathrm{L}$ was 47 days, compared to not reached for patients with $\mathrm{C}_{\text {trough }}<26.3 \mu \mathrm{g} / \mathrm{L}, p=0.0028$. 
Table 1 Baseline patient characteristics

\begin{tabular}{lclll}
\hline Characteristic & $\begin{array}{l}\text { All patients } \\
(n=55)\end{array}$ & $\begin{array}{l}\text { Control patients } \\
(n=34)\end{array}$ & $\begin{array}{l}\text { Obese patients } \\
(n=10)\end{array}$ & $\begin{array}{l}\text { Elderly patients } \\
(n=9)\end{array}$ \\
\hline Age (years), mean (SD) & $61.6(9.7)$ & $58.1(8.6)$ & $59.5(6.5)$ & $74.2(2.9)$ \\
BMI $\left(\mathrm{kg} / \mathrm{m}^{2}\right)$, mean (SD) & $26.2(4.4)$ & $24.4(3.0)$ & $32.8(3.0)$ & $24.6(1.9)$ \\
Number of previous treatment lines, mean (min-max) & & $1.9(0-3)$ & $0.8(0-3)$ \\
In adjuvant setting & $1.0(0-4)$ & $0.8(0-4)$ & $1.8(0-3)$ & $3.1(2-6)$ \\
In metastatic setting & $2.1(0-6)$ & $1.9(0-6)$ & $3.7(3-6)$ & $3.9(2-6)$ \\
Total & $3.2(1-6)$ & $2.8(1-6)$ & & 89 \\
Histology (\%) & 71 & 71 & 55 & 11 \\
$\quad \begin{array}{l}\text { Ductal carcinoma } \\
\text { Lobular carcinoma }\end{array}$ & 26 & 23 & & \\
\hline
\end{tabular}

\subsubsection{Relationship of $C_{\text {trough }}$ and Effectiveness}

GM everolimus $\mathrm{C}_{\text {trough }}$ of patients with and without PD $<3$ months was $12.0 \mu \mathrm{g} / \mathrm{L}$ and $15.2 \mu \mathrm{g} / \mathrm{L}$, respectively $(p=$ 0.118). ROC analysis to predict $P D<3$ months using $C_{\text {trough }}$ showed an $\mathrm{AUC}=0.64, p=0.15$. $\mathrm{C}_{\text {trough }}$ was a slightly better predictor of effectiveness than $\mathrm{AUC}_{0-24 \mathrm{~h}}$ with an $\mathrm{AUC}$ of 0.60 . The optimal cut-off value for $\mathrm{C}_{\text {trough }}$ was $<12.6 \mu \mathrm{g} / \mathrm{L}$, with sensitivity $69 \%$ and specificity $60 \%$. Twenty-one out of 43 patients $(48 \%)$ had an everolimus $\mathrm{C}_{\text {trough }}$ below this threshold. Nine of these 21 patients ( $43 \%$ ) had PD $<3$ months, compared to four out of $23(17 \%)$ patients with everolimus $\mathrm{C}_{\text {trough }}>12.6 \mu \mathrm{g} / \mathrm{L}$, resulting in a relative risk of 2.5 . No relevant difference was seen in the frequency of censoring in the Kaplan-Meier survival analysis, as four out of 21 patients were censored in the group patients with $\mathrm{C}_{\text {trough }}<12.6 \mu \mathrm{g} / \mathrm{L}$, and six out of 22 in the group patients with $\mathrm{C}_{\text {trough }}>$ $12.6 \mu \mathrm{g} / \mathrm{L}$. Median PFS time was not significantly different for patients with $\mathrm{C}_{\text {trough }}>12.6 \mu \mathrm{g} / \mathrm{L}$ and $<12.6 \mu \mathrm{g} / \mathrm{L}: 318$ versus 153 days respectively $(p=0.19)$, HR 0.85 (95\% CI 0.41-1.77) (Fig. 2).

The relationship between $\mathrm{C}_{\text {trough }}$ and PFS was different for the period of the first 365 days of treatment and after this period, as shown in a Cox regression analysis with timedependent $\mathrm{C}_{\text {trough }}$, dichotomized for above or below $12.6 \mu \mathrm{g} / \mathrm{L}$.

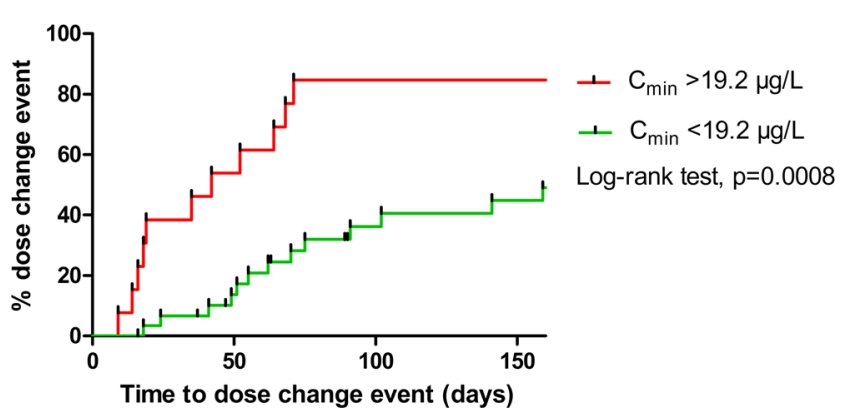

Fig. 1 Inverse Kaplan-Meier estimates of time to dose change event, based on differences in exposure
The outcomes of the effect of weight (obese) and age (elderly) on everolimus pharmacokinetics are presented in the Electronic supplementary material.

\subsection{Exploratory Outcomes: Response assessment Using FDG-PET}

Of all performed PET scans, 70 met the acquisition criteria as set by PERCIST. Lesions had sufficient FDG uptake in 20 of 22 patients $(91 \%)$ with ductal carcinoma, compared to eight of 12 patients $(67 \%)$ with lobular carcinoma.

ROC analysis showed that of sumSUL $\mathrm{L}_{\max }$, sumSUL $\mathrm{Leak}_{\text {pea }}$, $\mathrm{SUL}_{\text {peak high }}$, and sumTLG at day 14 and day 35, the percentage decrease in $\mathrm{SUL}_{\text {peak high }}$ at day $14\left(\mathrm{SUL}_{\text {peak high }} \mathrm{d} 14\right)$ was the best predictor of $\mathrm{PD}<3$ months. A cut-off of $11 \%$ decrease in $\mathrm{SUL}_{\text {peak high }} \mathrm{d} 14$ was optimal (Fig. 3), with an AUC of 0.78, sensitivity 0.78 , and specificity 0.84 . Patients with $\mathrm{PD}$ $<3$ months had a significantly lower mean decrease in $\mathrm{SUL}_{\text {peak high }} \mathrm{d} 14$ compared to patients without $\mathrm{PD}<3$ months: $7.1 \%$ versus $23.0 \%(p=0.02)$. Median PFS was 90 days for patients with $<11 \%$ decrease in $\mathrm{SUL}_{\text {peak high }} \mathrm{d} 14$, compared to 388 days for patients with $>11 \%$ decrease, $p=0.0013$ (Fig. 4). Seven out of ten patients $(70 \%)$ with $<11 \%$ decrease in SUL $_{\text {peak high }}$ d14 had PD $<3$ months, compared to two out of 18 patients $(11 \%)$ with a decrease $>11 \%$, resulting in a relative risk of 6.4 .

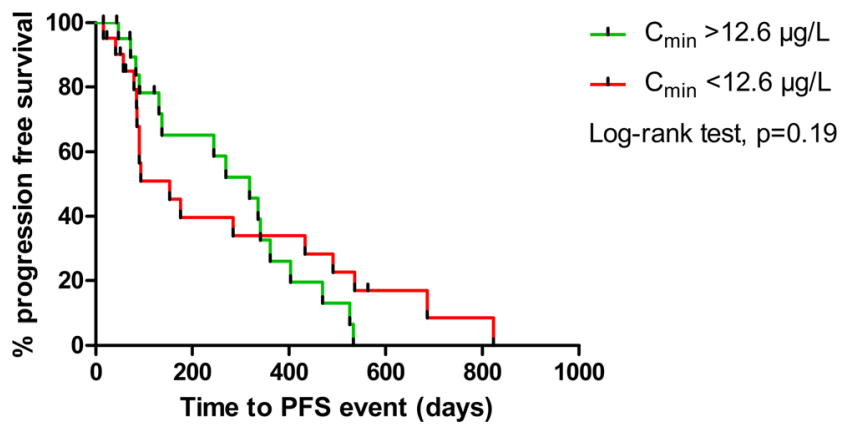

Fig. 2 Kaplan-Meier estimates of progression-free survival, based on differences in exposure 


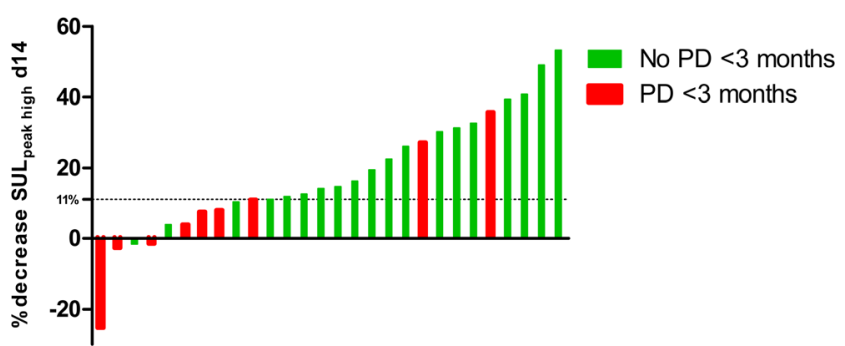

Fig. 3 Decrease in $\mathrm{SUL}_{\text {peak high }} \mathrm{d} 14$ for patients with and without progressive disease within 3 months. Each bar represents one patient

When using the European Organisation for Research and Treatment of Cancer (EORTC) response criteria of $>$ versus $<15 \%$ decrease in uptake in $\mathrm{SUL}_{\text {peak high }} \mathrm{d} 14$, median PFS was 440 versus 110 days $(p=0.0039)$. Using the PERCIST response criteria of $>$ versus $<30 \%$ decrease and $\geq 0.8 \mathrm{SUL}$ units in $\mathrm{SUL}_{\text {peak high }} \mathrm{d} 14$, median PFS was 440 versus 137 days $(p=0.115)$.

Using the qualitative assessment according to EORTC criteria, PERCIST criteria, and the consensus reading of two nuclear medicine physicians, the accuracy to predict RECIST classification after three months of treatment was poor, with $0.24,0.34$, and 0.39 , respectively. The negative predictive value of a partial metabolic response to predict the absence of progressive disease at three months according to EORTC criteria, PERCIST criteria, and the physician consensus reading was $0.78,0.88$, and 0.70 , respectively.

No significant correlation was found between everolimus $\mathrm{C}_{\text {trough }}$ and the decrease in $\mathrm{SUL}_{\text {peak high }} \mathrm{d} 14$ (Spearman's rho = $-0.31, p=0.108)$. Dose escalation did not result in a stronger decrease in metabolic activity between day 14 and 35 compared to no dose escalation ( $n=8$ vs. $n=17)$.

\subsection{Multivariable Analysis to Predict PFS}

The total number of previous lines of treatments in the adjuvant and metastatic settings was a significant predictor of PFS. Median PFS time was 341 days for patients with 1 to 3 previous treatments $(n=38)$ and 90 days for patients with 4 to 6 previous treatments $(n=19)(p=0.003)$, HR $0.32(95 \% \mathrm{CI}$ 0.15-0.86). Multivariable Cox regression analysis to estimate time to PFS event was performed using dichotomized $\mathrm{C}_{\text {trough }}$

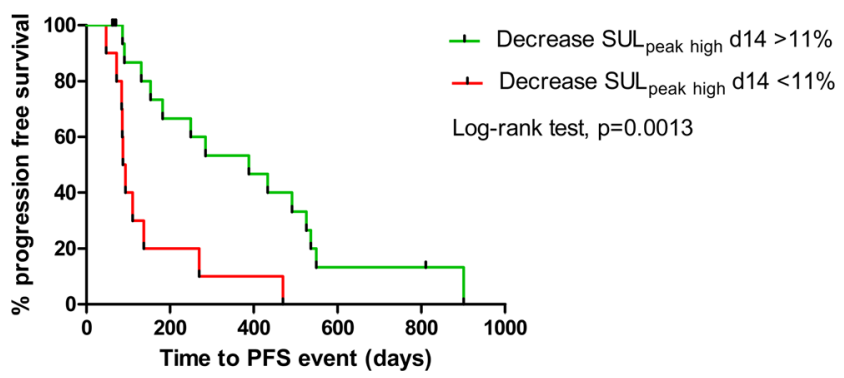

Fig. 4 Kaplan-Meier estimates of progression free survival, based on differences in metabolic/response at day 14 at day $14, \mathrm{SUL}_{\text {peak high }} \mathrm{d} 14$, and the number of previous treatments as covariates. Based on the plots of the Kaplan-Meier curves (Fig. 2), the HR for the dichotomized variable $\mathrm{C}_{\text {trough }}$ in the Cox proportional hazards model was allowed to be different before and after one year after diagnosis. From these covariates, $\mathrm{SUL}_{\text {peak high }} \mathrm{d} 14$ and the number of previous treatments were significantly associated with PFS (Table 2).

\section{Discussion}

The present study shows that patients with high everolimus trough concentrations $(>19.2 \mu \mathrm{g} / \mathrm{L})$ have a higher chance of clinically relevant toxicity leading to dose changes. It is clinically highly relevant to know that one third of patients are exposed to high everolimus $C_{\text {trough }}$, with a nearly threefold increased risk to develop toxicity, as this toxicity can potentially be prevented by dose adjustments.

The upper limit for toxicity that we found is comparable with the results of a recent, independently performed study [11]. As such, we were able to validate the importance of $\mathrm{C}_{\text {trough }}$ as a predictor of toxicity. If early dose reduction in the group of patients with $\mathrm{C}_{\text {trough }}>19.2 \mu \mathrm{g} / \mathrm{L}$ can reduce the dose change risk to the risk of patients with $\mathrm{C}_{\text {trough }}<19.2 \mu \mathrm{g} / \mathrm{L}$, severe toxicity could potentially be prevented in $\sim 50 \%$ of these patients.

Secondly, we show that, as early as 14 days after start of treatment, FDG-PET can identify a subgroup of patients with a high risk of nonresponse to everolimus and exemestane. To our knowledge, this is the first prospective evaluation of the value of FDG-PET to predict outcomes of treatment with everolimus and exemestane in $\mathrm{mBC}$ patients. A decrease in $\mathrm{SUL}_{\text {peak high }} \mathrm{d} 14$ of $<11 \%$ was found to be the best predictor for early PD, but the cutoff as proposed by EORTC ( $\geq 15 \%$ decrease) was a significant predictor as well. The cut-off used in the PERCIST classification ( $\geq 30 \%$ decrease) in this study was not a significant predictor. Perhaps the criterion of PERCIST is too stringent for response monitoring of agents that inhibit the activity of oncogenic proteins. If a patient has a poor decline in metabolic activity on FDG-PET at day 14, the treating physician can consider to adjust therapy or to follow this patient extra cautiously. This can aid to give patients optimal outcomes from their anticancer therapy and to avoid side effects and costs of an ineffective treatment. Additionally, lobular carcinomas more frequently had lesions

Table 2 Cox proportional hazards model for time to PFS event

\begin{tabular}{llll}
\hline & HR & $95 \% \mathrm{CI}$ & $P$ value \\
\hline $\mathrm{C}_{\text {trough }}$ at day $14>$ or $<12.6 \mu \mathrm{g} / \mathrm{L}^{\mathrm{a}}$ & 0.999 & $0.904-1.103$ & 0.978 \\
$\mathrm{SUL}_{\text {peak high }} \mathrm{d} 14$ & 0.960 & $0.932-0.990$ & 0.087 \\
Number of previous treatments & 1.352 & $0.957-1.910$ & 0.009 \\
\hline
\end{tabular}

a, $\mathrm{C}_{\text {trough }}<12.6 \mu \mathrm{g} / \mathrm{L}$ served as the reference group

SUL, standardized uptake values normalized by lean body weight 
with low FDG activity, consistent with earlier experiences [32], but the majority of lobular carcinomas were suitable for FDGPET response monitoring.

In our data, $\mathrm{C}_{\text {trough }}$ was no significant predictor of effectiveness. The relatively small sample size of our study increases the chance that we were not able to demonstrate a difference between these groups. A previous study did show a significant relationship between $\mathrm{C}_{\text {trough }}$ and effectiveness [11]. Another study showed no correlation between dose intensity and response rate or PFS, but no everolimus concentrations were measured in that study [33]. The weak relationship between everolimus $\mathrm{C}_{\text {trough }}$ and outcomes can be explained by the presence of exemestane-sensitive tumors that would also have responded without adding everolimus to the treatment. This also can explain the crossing of the PFS survival curves that was seen in our data (Fig. 2). Unfortunately, up to now it cannot be predicted which tumors are exemestane-sensitive and do not need the combination with everolimus treatment. The fact that no relationship was seen between everolimus $\mathrm{C}_{\text {trough }}$ and metabolic response supports the notion that other factors influence the effectiveness of everolimus and exemestane besides everolimus $\mathrm{C}_{\text {trough }}$.

An additional finding of this study, described in the supplementary file, was that no significant effect of elderly age and obesity was established on everolimus $\mathrm{C}_{\text {trough }}$. However, due to the small sample size there was limited power to detect a possible difference, and no firm conclusions can be drawn. Elderly patients more frequently had dose changes due to toxicity compared to control patients. This is in contrast with a previous study in which everolimus dose modifications were not seen more frequently in patients of $\geq 70$ years $(n=118)$ compared to patients $<70$ years $(n=364)$ [34].

Furthermore, we have shown that $\mathrm{C}_{\text {trough }}$ is a better predictor for toxicity and effectiveness compared to a full AUC with eight measurements. The importance of $\mathrm{C}_{\text {trough }}$ compared to AUC was also demonstrated in a recent preclinical study showing that continuous low dosing above a certain threshold can be as effective as intermittent dosing with a higher AUC [35]. It has substantial practical benefits if the collection of only one blood sample is sufficient and even superior.

The strong points of our study are the prospective nature of our study with the collection of extensive pharmacokinetic data. Our pharmacokinetic results are in agreement with the findings of several other studies.

Our study also has limitations. Firstly, the sample size of our study is relatively small. Hence, this is an exploratory, hypothesis generating, study. Furthermore, the value of FDG-PET as an early read-out is limited by the fact that very few patients are classified as PD after three months. As such, it was not possible to identify individuals with $100 \%$ chance on early progression.

To advance the care for patients with $\mathrm{mBC}$, we need to further individualize treatment in order to improve effectiveness and reduce toxicity. The most important finding to emerge from this study is that monitoring everolimus $\mathrm{C}_{\text {trough }}$ has the potential to identify patients at high risk of developing toxicity. For the future, a patient should have everolimus $\mathrm{C}_{\text {trough }}$ determined seven days after start of treatment, so that toxicity potentially can be prevented through early dose adjustments. A prospective evaluation to study whether therapeutic drug monitoring to reach everolimus drug concentrations in a target window leads to better patient outcomes is currently ongoing (M17 TDM study). Furthermore, after start of treatment a poor decrease in metabolic activity at day 14 on FDG-PET seems to be an important signal of possible ineffective treatment, but these results require further validation.

Acknowledgements First of all, we thank all the patients that were willing to participate in this study. Further we would like to thank the project staff of all participating hospitals in acquiring the data.

\section{Compliance with Ethical Standards}

Funding This study was funded by a grant from Novartis (grant number 2878/13). This article was published open access under a Springer Compact agreement with Dutch universities and Academy institutes.

Conflict of Interest Maaike de Boer received an institutional grant from Novartis for research. Carla M.L. van Herpen and Nielka P. van Erp received an institutional grant from Novartis to perform this study. Annelieke E.C.A.B. Willemsen, Lioe-Fee de Geus-Oei, Jolien Tol, Yvonne Kamm, Paul C. de Jong, Marianne A. Jonker, Allert H. Vos, Willem Grootjans, Johannes W.B. de Groot, Sasja F. Mulder, Erik H.J.G. Aarntzen, and Winald R. Gerritsen declare that they have no conflicts of interest that might be relevant to the contents of this manuscript.

Open Access This article is distributed under the terms of the Creative Commons Attribution-NonCommercial 4.0 International License (http:// creativecommons.org/licenses/by-nc/4.0/), which permits any noncommercial use, distribution, and reproduction in any medium, provided you give appropriate credit to the original author(s) and the source, provide a link to the Creative Commons license, and indicate if changes were made.

\section{References}

1. Baselga J, Campone M, Piccart M, Burris HA 3rd, Rugo HS, Sahmoud $\mathrm{T}$, et al. Everolimus in postmenopausal hormone-receptor-positive advanced breast cancer. N Engl J Med. 2012;366(6):520-9.

2. Lousberg L, Jerusalem G. Safety, efficacy, and patient acceptability of everolimus in the treatment of breast Cancer. Breast Cancer. 2016;10:239-52.

3. Li N, Hao Y, Xie J, Lin PL, Koo V, Ohashi E, et al. Effectiveness of verolimus versus endocrine monotherapy or chemotherapy among HR+/HER2- mBC patients with multiple metastatic sites. Clin Ther. 2016;38(4):905-17.

4. Lin PL, Hao Y, Xie J, Li N, Ohashi E, Koo V, et al. Real-world effectiveness of everolimus-based therapy versus endocrine monotherapy and chemotherapy in patients of HR+/HER2- breast cancer with liver metastasis in the USA. Expert Opin Pharmacother. 2015;16(14):2101-11.

5. Yardley DA, Noguchi S, Pritchard KI, Burris HA 3rd, Baselga J, Gnant M, et al. Everolimus plus exemestane in postmenopausal 
patients with $\mathrm{HR}(+)$ breast cancer: BOLERO-2 final progressionfree survival analysis. Adv Ther. 2013;30(10):870-84.

6. Jerusalem G, Mariani G, Ciruelos EM, Martin M, Tjan-Heijnen VC, Neven P, et al. Safety of everolimus plus exemestane in patients with hormone-receptor-positive, HER2-negative locally advanced or metastatic breast cancer progressing on prior nonsteroidal aromatase inhibitors: primary results of a phase IIIb, open-label, single-arm, expanded-access multicenter trial (BALLET). Ann Oncol. 2016;27(9):1719-25.

7. US Food and Drug Administration. Everolimus (Afinitor). Clinical pharmacology and biopharmaceutics review. 2008. Available at http://www.accessdata.fda.gov/drugsatfda_docs/nda/2009/ 022334s000TOC.cfm. Accessed 25th January 2013.

8. O'Donnell A, Faivre S, Burris HA 3rd, Rea D, Papadimitrakopoulou $\mathrm{V}$, Shand $\mathrm{N}$, et al. Phase I pharmacokinetic and pharmacodynamic study of the oral mammalian target of rapamycin inhibitor everolimus in patients with advanced solid tumors. J Clin Oncol. 2008;26(10): 1588-95.

9. Awada A, Cardoso F, Fontaine C, Dirix L, De Greve J, Sotiriou C, et al. The oral mTOR inhibitor RAD001 (everolimus) in combination with letrozole in patients with advanced breast cancer: results of a phase I study with pharmacokinetics. Eur J Cancer. 2008;44(1):84-91.

10. van Erp NP, van Herpen CM, de Wit D, Willemsen A, Burger DM, Huitema AD, et al. A semi-physiological population model to quantify the effect of hematocrit on Everolimus pharmacokinetics and pharmacodynamics in Cancer patients. Clin Pharmacokinet. 2016;55(11):1447-56.

11. Deppenweiler M, Falkowski S, Saint-Marcoux F, Monchaud C, Picard N, Laroche ML, et al. Towards therapeutic drug monitoring of everolimus in cancer? Results of an exploratory study of exposure-effect relationship. Pharmacol Res. 2017;121:138-44.

12. Ravaud A, Urva SR, Grosch K, Cheung WK, Anak O, Sellami DB. Relationship between everolimus exposure and safety and efficacy: meta-analysis of clinical trials in oncology. Eur J Cancer. 2014;50(3):486-95.

13. Thiery-Vuillemin A, Mouillet G, Nguyen Tan Hon T, Montcuquet P, Maurina T, Almotlak H, et al. Impact of everolimus blood concentration on its anti-cancer activity in patients with metastatic renal cell carcinoma. Cancer Chemother Pharmacol. 2014;73(5):999-1007.

14. Verheijen RB, Yu H, Schellens JHM, Beijnen JH, Steeghs N, Huitema ADR. Practical recommendations for therapeutic drug monitoring of kinase inhibitors in oncology. Clin Pharmacol Ther. 2017;102(5):765-76.

15. Hunt CM, Watkins PB, Saenger P, Stave GM, Barlascini N, Watlington $\mathrm{CO}$, et al. Heterogeneity of CYP3A isoforms metabolizing erythromycin and cortisol. Clin Pharmacol Ther. 1992;51(1):18-23.

16. Blouin RA, Warren GW. Pharmacokinetic considerations in obesity. J Pharm Sci. 1999;88(1):1-7.

17. Grassi M, Petraccia L, Mennuni G, Fontana M, Scarno A, Sabetta $\mathrm{S}$, et al. Changes, functional disorders, and diseases in the gastrointestinal tract of elderly. Nutr Hosp. 2011;26(4):659-68.

18. Schmucker DL. Liver function and phase I drug metabolism in the elderly: a paradox. Drugs Aging. 2001;18(11):837-51.

19. Le Couteur DG, McLean AJ. The aging liver. Drug clearance and an oxygen diffusion barrier hypothesis. Clin Pharmacokinet. 1998;34(5):359-73.

20. Hilmer SN, Shenfield GM, Le Couteur DG. Clinical implications of changes in hepatic drug metabolism in older people. Ther Clin Risk Manag. 2005;1(2):151-156.
21. Honer M, Ebenhan T, Allegrini PR, Ametamey SM, Becquet M, Cannet $\mathrm{C}$, et al. Anti-Angiogenic/vascular effects of the mTOR inhibitor Everolimus are not detectable by FDG/FLT-PET. Transl Oncol. 2010;3(4):264-75.

22. Nogova L, Boellaard R, Kobe C, Hoetjes N, Zander T, Gross SH, et al. Downregulation of 18 F-FDG uptake in PET as an early pharmacodynamic effect in treatment of non-small cell lung cancer with the mTOR inhibitor everolimus. J Nucl Med. 2009;50(11):1815-9.

23. Cejka D, Kuntner C, Preusser M, Fritzer-Szekeres M, Fueger BJ, Strommer S, et al. FDG uptake is a surrogate marker for defining the optimal biological dose of the mTOR inhibitor everolimus in vivo. Br J Cancer. 2009;100(11):1739-45.

24. Wei LH, Su H, Hildebrandt IJ, Phelps ME, Czernin J, Weber WA. Changes in tumor metabolism as readout for mammalian target of rapamycin kinase inhibition by rapamycin in glioblastoma. Clin Cancer Res. 2008;14(11):3416-26.

25. Thomas GV, Tran C, Mellinghoff IK, Welsbie DS, Chan E, Fueger $\mathrm{B}$, et al. Hypoxia-inducible factor determines sensitivity to inhibitors of mTOR in kidney cancer. Nat Med. 2006;12(1):122-7.

26. Chen JL, Appelbaum DE, Kocherginsky M, Cowey CL, Rathmell WK, McDermott DF, et al. FDG-PET as a predictive biomarker for therapy with everolimus in metastatic renal cell cancer. Cancer Med. 2013;2(4):545-52.

27. Mortazavi-Jehanno N, Giraudet AL, Champion L, Lerebours F, Le Stanc E, Edeline V, et al. Assessment of response to endocrine therapy using FDG PET/CT in metastatic breast cancer: a pilot study. Eur J Nucl Med Mol Imaging. 2012;39(3):450-60.

28. Dose Schwarz J, Bader M, Jenicke L, Hemminger G, Janicke F, Avril N. Early prediction of response to chemotherapy in metastatic breast cancer using sequential 18F-FDG PET. J Nucl Med. 2005;46(7):1144-50.

29. Eisenhauer EA, Therasse P, Bogaerts J, Schwartz LH, Sargent D, Ford $\mathrm{R}$, et al. New response evaluation criteria in solid tumours: revised RECIST guideline (version 1.1). Eur J Cancer. 2009;45(2):228- 47.

30. Janmahasatian S, Duffull SB, Ash S, Ward LC, Byrne NM, Green B. Quantification of lean bodyweight. Clin Pharmacokinet. 2005;44(10):1051-65.

31. Wahl RL, Jacene H, Kasamon Y, Lodge MA. From RECIST to PERCIST: evolving considerations for PET response criteria in solid tumors. J Nucl Med. 2009;50(Suppl 1):122S-50S.

32. Fujii T, Yajima R, Kurozumi S, Higuchi T, Obayashi S, Tokiniwa $\mathrm{H}$, et al. Clinical significance of 18F-FDG-PET in invasive lobular carcinoma. Anticancer Res. 2016;36(10):5481-5.

33. Ciccarese M, Fabi A, Moscetti L, Cazzaniga ME, Petrucelli L, Forcignano R, et al. Dose intensity and efficacy of the combination of everolimus and exemestane (EVE/EXE) in a real-world population of hormone receptor-positive (ER+/PgR+), HER2-negative advanced breast cancer $(\mathrm{ABC})$ patients: a multicenter Italian experience. Breast Cancer Res Treat. 2017;163(3):587-94.

34. Pritchard KI, Burris HA 3rd, Ito Y, Rugo HS, Dakhil S, Hortobagyi GN, et al. Safety and efficacy of everolimus with exemestane vs. exemestane alone in elderly patients with HER2-negative, hormone receptor-positive breast cancer in BOLERO-2. Clin Breast Cancer. 2013;13(6):421-32 e8.

35. Laborde L, Oz F, Ristov M, Guthy D, Sterker D, McSheehy P. Continuous low plasma concentrations of everolimus provides equivalent efficacy to oral daily dosing in mouse xenograft models of human cancer. Cancer Chemother Pharmacol. 2017;80(4):869-78. 